\title{
Modeling the Tide-Induced Modulation of Wave Height in the Outer Seine Estuary
}

\author{
Nicolas Guillou* and Georges Chapalain \\ Centre d'Etudes Techniques Maritimes Et Fluviales (CETMEF) \\ Laboratoire de Génie Côtier et Environnement (LGCE) \\ 155 rue Pierre Bouguer Technopôle Brest Iroise - BP 5 - 29280 Plouzané, France \\ Tél.: +33 (0)2 98056739 \\ Fax: 0298056721 \\ E-mails: nicolas.guillou@developpement-durable.gouv.fr \\ georges.chapalain@developpement-durable.gouv.fr \\ * corresponding author
}

\begin{abstract}
During the last decades, numerous models have been implemented to investigate the effects of tide on wind-generated surface-gravity waves. The present study analyzes the influences of the tideinduced time-varying water depths and currents on the wave height in the outer Seine estuary (France, English Channel). Two modeling systems based on the coupling of circulation and wave propagation modules are applied at the scales of (i) the English Channel and the North Sea and (ii) the Bay of Seine and the harbor of Le Havre, respectively. Numerical results are compared with field data collected with two current meters and two wave buoys in the access channel to Port 2000 (Le Havre). Predictions exhibit a local increase by $30 \%$ of the wave height induced by current refraction at slack tide. On the basis of this local comparison of numerical results with measurements, three mappings of the wave height modified by (i) the tide, (ii) the water levels alone and (iii) the currents alone are established at the scale of the outer Seine estuary. The currents have a major influence on the wave height modulating at a tidal frequency the exposure to incident waves through refraction. This effect is exhibited along the southern breakwater of the harbor of Le Havre and the vicinity of coastal topographic features of the outer Seine estuary.
\end{abstract}

ADDITIONAL INDEX WORDS

Bay of Seine, English Channel, Port 2000, Le Havre, current, refraction, MISTRAL, TELEMAC, COHERENS, SWAN, TOMAWAC

\section{INTRODUCTION}

The knowledge of the nearshore waves conditions is fundamental for many coastal and civil engineering applications such as the quantification of the sediment transport rates, the ship routing regulations or the design of coastal protections. In the last decades, an increasing interest has thus been brought to the effects of the tide-induced time-varying water depths and currents on the waves propagation in shallow waters (e.g., Longuet-Higgins and Stewart, 1960; Huang et al., 1972; Jonsson, 1990). The most famous aspects of these interactions has recently been reviewed by Holthuijsen (2007) and Davidson, O'Hare and George (2008). The variation of the water depths modulates the dissipation of the wave energy by bottom friction and the wave breaking. Opposing tidal flow induces steepening of the incident wave field thus increasing the wave height. Finally, the combination of time-varying water depths and currents leads to wave refraction and a semi-diurnal 
variability of the incident wave energy at specific coastal locations. A noticeable resulting effect of these processes is the tidal modulation of the wave height in the coastal region.

Numerical modeling systems have been set up to gain a further insight of these interactions. Claasen (2002) established a guideline of the couplings to consider in relation to the climatology of wave and tide. This was followed by numerous numerical applications exhibited the significance of the tidal flow on the wave height variation in estuaries (e.g., Milbradt and Plüß, 2003; Wang et al., 2006; Rusu and Guedes Soares, 2007). The system performance was evaluated by comparing predictions with wave measurements characterized by tidal modulations (e.g., Kang and Di Iorio, 2006; Sørensen, Kofoed-Hansen and Jones, 2006; Rusu, Bernardino and Soares, 2011). More recently, Liu and Xie (2009) have analyzed the respective effects of the water levels and currents on the wave height for hurricane conditions.

The purpose of the present study is to investigate the effects of the tide-induced time-varying water depths and currents on the wave height relying on a long-term comparison between predictions and measurements characterized by noticeable semi-diurnal variations. The application is dedicated to the outer Seine estuary (France, English Channel) (Figure 1) characterized by strong interactions between wave and tide with (i) spring tidal range of $7 \mathrm{~m}$ and current amplitude of $1.5 \mathrm{~m}$ $\mathrm{s}^{-1}$ (SHOM, 1996) and annually wave height over $5 \mathrm{~m}$ offshore (Lesourd, 2000).

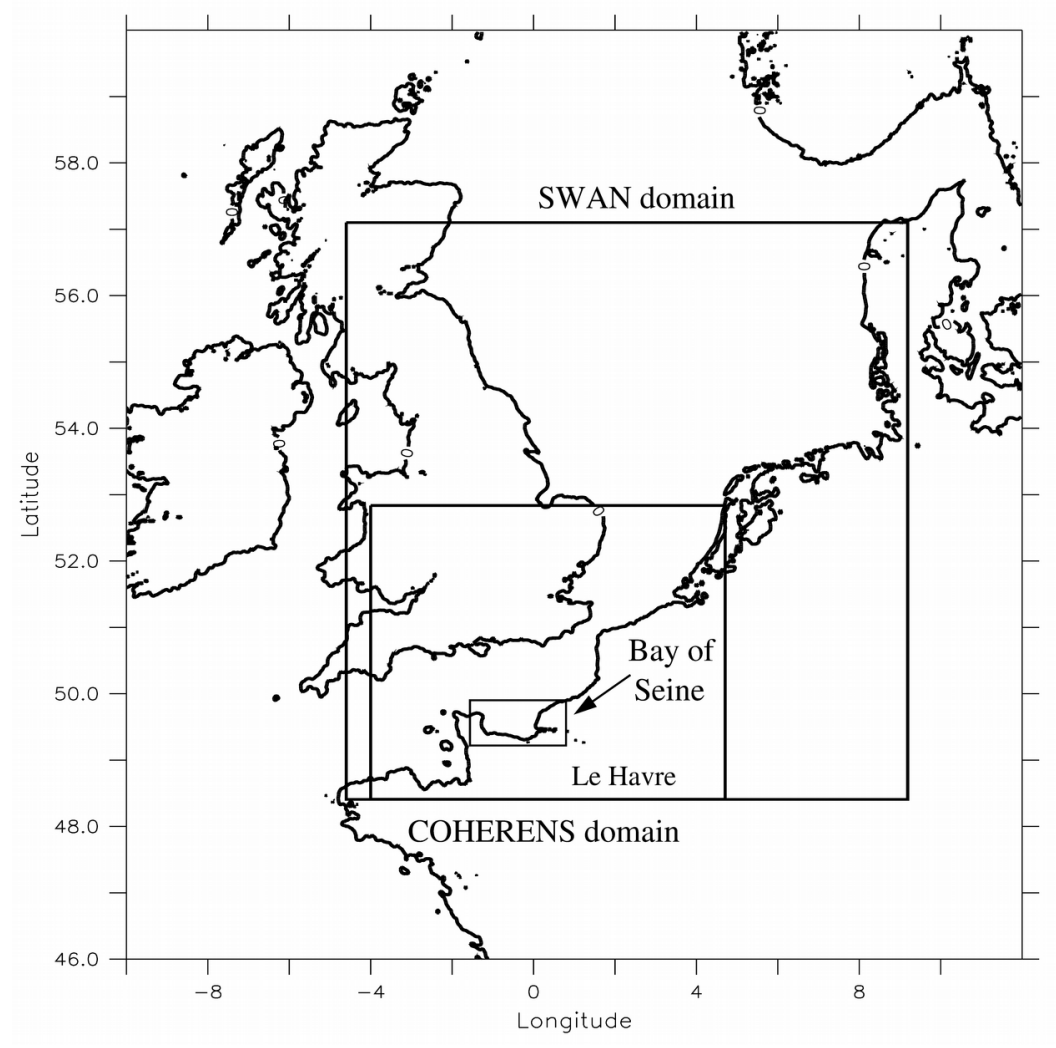

Figure 1: SWAN and COHERENS computational domains.

The modeling is based on the coupling of wave propagation and circulation modules at the scales of (i) the English Channel and the North Sea and (ii) the Bay of Seine and the harbor of Le Havre (Figure 1). The coupling is restricted to the three modifications of the wave parameters by the water depths and the currents (bottom friction, wave steepening and refraction) and the effects of the interaction between the wave and current bottom boundary layers (Grant and Madsen, 1979). Numerical results are compared with field data collected with two current meters and two wave buoys in the access channel to Port 2000 (harbor of Le Havre). The local increase of the wave height under the effect of the tide is quantified. Three mappings of the wave height modified by (i) 
the tide, (ii) the water levels alone and (iii) the currents alone are established at the scale of the outer Seine estuary. Finally, the effects of current-induced refraction on the wave propagation are investigated further as a major process determining the tidal modulation of the wave height in the coastal region.

\section{MATERIALS AND METHODS}

\section{Models Description}

Simulations are performed with the two nesting modeling systems (i) MISTRAL (Modélisation Intégrée pour la Simulation des TRAnsports Littoraux) (Guillou, 2007) at the regional scale of the English Channel and the North Sea (Figure 1) and (ii) TELEMAC (Benoit, Marcos and Becq, 1996; Hervouet, 2003) at the local scale of the Bay of Seine (Figure 2). Each modeling system couples circulation and wave propagation modules. The coupling procedure is restricted to (i) the modifications of the wave fields by the time-varying water depths and currents and (ii) the interaction between the wave and current bottom boundary layers ignoring the generation of currents by the waves.

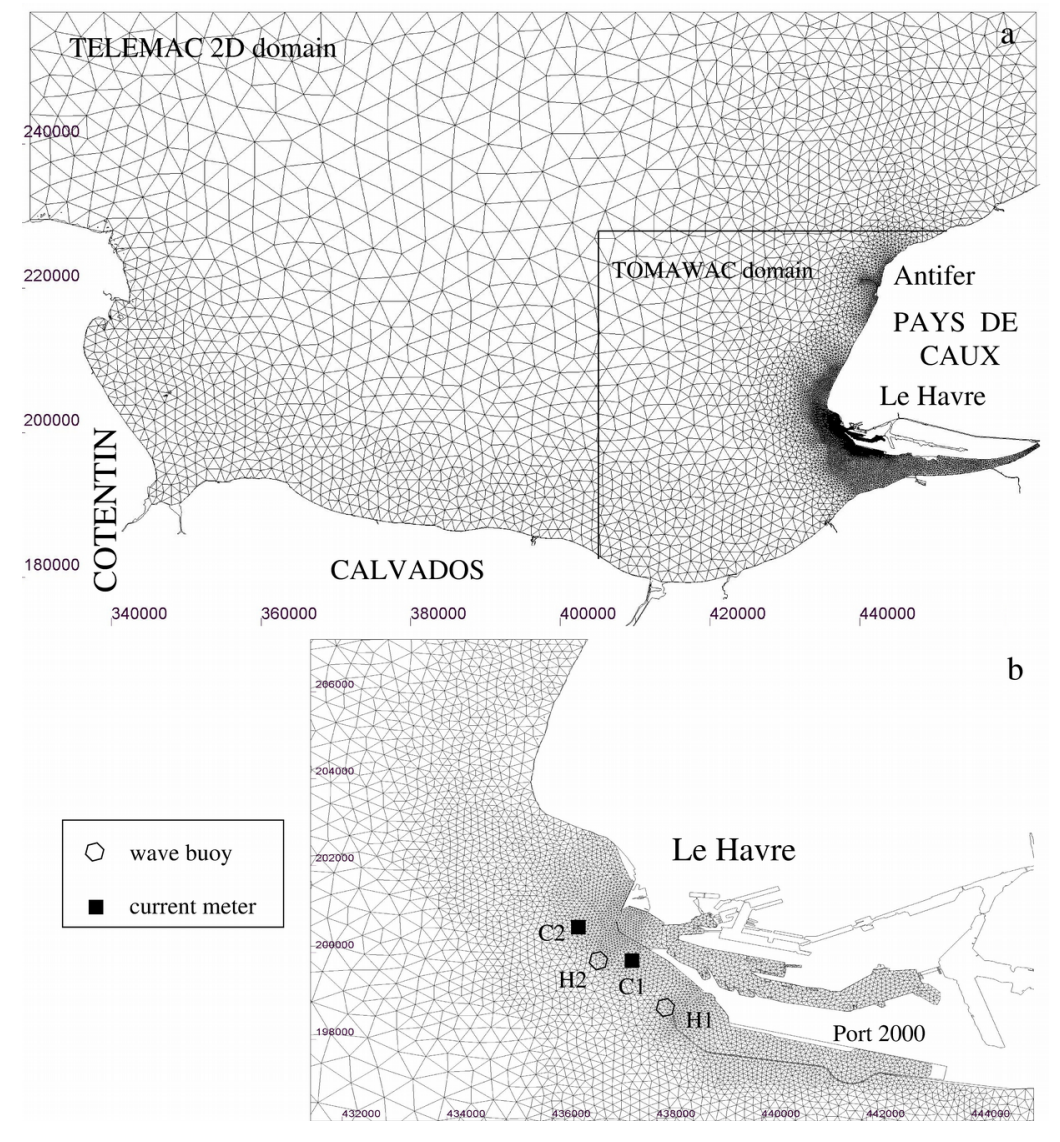

Figure 2: (a) TOMAWAC and TELEMAC 2D computational domains. (b) Close-up of the computational mesh near the harbor of Le Havre with the locations of the current meters and wave buoys. The coordinates are indicated in meters according to the French system Lambert I Nord.

MISTRAL is based on the coupling of the wave propagation module SWAN (Simulating WAves Nearshore) (Booij, Ris and Holthuijsen, 1999) with the three-dimensional (3D) circulation module COHERENS (COupled Hydrodynamical Ecological model for RegioNal and Shelf seas) (Luyten et al., 1999). This coupling considers in COHERENS the increase of the apparent bottom roughness parameter felt by the current above the wave boundary layer according to Grant and 
Madsen (1979). It integrates in SWAN the effects of the time-varying water depths and ambient currents. Further details about the MISTRAL modeling system are available in Guillou (2007), Guillou, Chapalain and Thais (2009) and Guillou and Chapalain (2010a).

TELEMAC couples the wave propagation module TOMAWAC (Benoit, Marcos and Becq, 1996) with the bidimensional horizontal (2DH) circulation module TELEMAC 2D (Hervouet, 2003). The processes considered in the coupling are similar to those incorporated in MISTRAL. The difference lies in the computation of the apparent roughness parameter performed with the method of Signell et al. (1990).

The coupling between the wave propagation and circulation modules is realized performing computations one after another. SWAN is first launched at the regional scale of the English Channel and the North Sea neglecting the effects of the time-varying water depths and currents. Waves output fields are provided to the sub-module of COHERENS computing the interactions between the wave and current bottom boundary layers. Predicted fields of free surface elevations and depthaveraged currents issued from COHERENS are then introduced as input forcings in SWAN at the scale of the English Channel and the southern North sea (Figure 1). Waves output fields are provided to TELEMAC 2D to compute the apparent roughness parameter. Finally, the time-varying water depths and currents issued from TELEMAC 2D are integrated in TOMAWAC simulations at the scale of the outer Seine estuary (Figure 2). The different type of data used as boundary conditions, meteorological and hydrodynamic fields are interpolated at all grid points and every time steps of the wave propagation and circulation modules considered.

\section{Models Setup}

SWAN is implemented on a $301 \times 301$ horizontal regular grid with a resolution of $3 \mathrm{~km}$ extending in longitude from $4^{\circ} 600 \mathrm{~W}$ to $9^{\circ} 189 \mathrm{E}$ and in latitude from $48^{\circ} 408 \mathrm{~N}$ to $57^{\circ} 101 \mathrm{~N}$ (Figure 1). The module runs with 30 exponentially spaced frequencies ranging from $0.05 \mathrm{~Hz}$ to 1 $\mathrm{Hz}, 60$ evenly spaced directions ( $6^{\circ}$ resolution) and a time step of $5 \mathrm{~min}$. The sink term of dissipation by bottom friction is parameterized with an uniform bottom friction coefficient $\mathrm{C}_{b}=0.038 \mathrm{~m}^{2} \mathrm{~s}^{-3}$ according to Hasselmann et al. (1973). SWAN is driven by the wave components extracted every 30 min at 5 points along each open boundary from a regional run of WaveWatch III (Tolman, 2008) on the North-West European continental shelf (Fabrice Ardhuin, Institut Français de Recherche pour l'Exploitation de la MER, France, personal communication, 2010). Wind velocity components $10 \mathrm{~m}$ above the free surface are obtained from the database of the National Centers for Environmental Predictions (NCEP) (Kanamitsu et al., 2002). The free-surface elevations and the currents are extracted from COHERENS computations at one hour intervals.

COHERENS is set-up on a $196 \times 165$ horizontal regular grid with a resolution of $2 \mathrm{~km}$ extending from $4^{\circ} 000 \mathrm{~W}$ to $4^{\circ} 707 \mathrm{E}$ and $48^{\circ} 410 \mathrm{~N}$ to $52^{\circ} 837 \mathrm{~N}$ (Figure 1). The module has 11 uniform vertical $\sigma$ grid cells. The time steps for the external barotropic and internal baroclinic modes are 30 and $300 \mathrm{~s}$, respectively. In an inner domain extended from $3^{\circ} 300 \mathrm{~W}$ to $3^{\circ} 000 \mathrm{E}$ and $48^{\circ} 410 \mathrm{~N}$ to $51^{\circ} 300 \mathrm{~N}$, the bottom roughness is derived from the granulometric distribution of seabed sediments interpolated at all grid nodes from a series of bottom sediment samples (Guillou and Chapalain, 2010b). The bottom roughness parameter is set to $0.0035 \mathrm{~m}$ elsewhere. COHERENS is driven by the dominant tidal constituents extracted from a long-term run of its 2DH version on the North-West European continental shelf (José Ozer, Management Unit of the North Sea Mathematical Models, Belgium, personal communication, 1999). The tidal signal is predicted every $10 \mathrm{~min}$ at 15 points along each open boundary. Wind forcings from the NCEP database are also integrated. Finally, SWAN outputs are provided at one hour intervals.

TOMAWAC is implemented on a domain close to the Seine estuary extending from $0^{\circ} 245 \mathrm{~W}$ to $0^{\circ} 354 \mathrm{E}$ and $49^{\circ} 253 \mathrm{~N}$ to $49^{\circ} 743 \mathrm{~N}$ (Figure 2). The computational mesh comprises 2,462 nodes and 4,507 finite elements with a size of $2 \mathrm{~km}$ offshore to a few tens of meters close to the harbor of Le Havre. The time step is set to $20 \mathrm{~s}$. The implementation of the wave propagation module retains 
the same parameterization of the bottom friction and the discretization of the wave energy density as in SWAN. The number of directions is however reduced to 15 with a resolution of $24^{\circ}$ to optimize the computation time. Preliminary tests show that this discretization provides results consistent with the use of a greater number of directions. Such selection is similar to Sørensen, Kofoed-Hansen and Jones (2006) who retained 16 directions for their numerical study of the wavecurrent interaction in the Bristol Channel (United-Kingdom). TOMAWAC is driven by the wave components extracted every $90 \mathrm{~min}$ from SWAN regional simulations. The time-varying water depths and currents are given every 30 min by TELEMAC 2D.

TELEMAC 2D is set-up on a domain covering the Bay of Seine between the longitudes $1^{\circ} 380$ $\mathrm{W}$ and $0^{\circ} 433 \mathrm{E}$ and the latitudes $49^{\circ} 253 \mathrm{~N}$ and $50^{\circ} 005 \mathrm{~N}$ (Figure 2). The computational domain comprises 8,708 nodes and 16,414 finite elements with a size of $4 \mathrm{~km}$ offshore to a few tens of meters close to the harbor of Le Havre. The time step is set to $10 \mathrm{~s}$. The bottom friction coefficient is computed with a Chezy's law and the heterogeneous roughness parameter derived from the observed grain size distribution dataset (Guillou and Chapalain, 2010b). The circulation module incorporates the wind fields from the NCEP database. TELEMAC 2D is driven by the free surface elevations and the depth-averaged currents extracted at one hour intervals from COHERENS regional simulations. The wave fields are provided every $90 \mathrm{~min}$ from SWAN regional simulations. Finally, an average flow of $450 \mathrm{~m}^{3} \cdot \mathrm{s}^{-1}$ is prescribed at the entrance of the Seine river (e.g., Waeles, 2005).

In order to investigate the effects of the time-varying water depths and currents on the wave height, four experiments are conducted on the wave propagation modules SWAN and TOMAWAC (Table 1). In case NN, the waves modules are run without the effects of the tide. SWAN and TOMAWAC integrate the tide-induced time-varying water depths and currents in cases NS and CN, respectively. Finally, the global effects of the tide are implemented in case CS. Preliminary tests exhibited the negligible impact of the interactions between the wave and current bottom boundary layers on the hydrodynamics computed by the circulation module, i.e. the free surface elevation and the current. This makes it easier to compare the effects of these two parameters between cases CS, NS and CN.

\section{Experiment Description}

Measurements here used were made in the access channel to Port 2000 (harbor of Le Havre) in mean water depths of $19 \mathrm{~m}$ (Figure 2). The instrumentation consists of (i) two current meters C1 $\left(\lambda=0^{\circ} 091 \mathrm{E}, \Phi=49^{\circ} 476 \mathrm{~N}\right)$ and $\mathrm{C} 2\left(\lambda=0^{\circ} 077 \mathrm{E}, \Phi=49^{\circ} 484 \mathrm{~N}\right)$ and (ii) two wave buoys $\mathrm{H} 1\left(\lambda=0^{\circ} 104\right.$ E, $\left.\Phi=49^{\circ} 465 \mathrm{~N}\right)$ and $\mathrm{H} 2\left(\lambda=0^{\circ} 087 \mathrm{E}, \Phi=49^{\circ} 475 \mathrm{~N}\right)$.

The current measurements were realized over the two spring tide periods of 15-16 November 2005 at point C2 and 2-3 January 2006 at point C1. The instrumentation is an upward looking Acoustic Doppler Current Profiler (ADCP) placed on the bottom.

The wave measurements were implemented at points $\mathrm{H} 1$ and $\mathrm{H} 2$ as part of an observational system to regulate the ship routing close to the harbor of Le Havre. The period analyzed here is the month of November 2008 characterized by continuous records with a tidal range of $7 \mathrm{~m}$ in 14 November 2008 at the harbor of Le Havre and a significant wave height of $2.8 \mathrm{~m}$ in 23 November 2008 at point $\mathrm{H} 1$.

Table 1: List of experiments for the wave propagation modules SWAN and TOMAWAC.

\begin{tabular}{llll} 
Experiments & Cases & Time-varying water depths & Time-varying currents \\
\hline 1 & NN & No & No \\
2 & NS & Yes & No \\
3 & CN & No & Yes \\
4 & CS & Yes & Yes \\
\hline
\end{tabular}




\section{RESULTS AND DISCUSSION}

\section{Comparison of Model Predictions With Point Measurements}

The emphasis is put on the local comparison of model predictions with measurements in the vicinity of the harbor of Le Havre (Figure 2) whereas the quality of regional simulations with the MISTRAL modeling system has been estimated. COHERENS numerical results fit thus fairly well with water depths observations in French harbors issued from the tide gauge network RONIM ("Réseau d'Observation du NIveau de la Mer") and currents measurements supplied by the SHOM ("Service Hydrographique et Océanographique de la Marine”) for the month of November 2008. Further confirmations of the numerical results issued from the circulation module have been performed in the eastern English Channel (Guillou, Chapalain and Thais, 2009). SWAN numerical results are also in overall good agreement for the month of November 2008 with measurements of the wave height, period and direction at the three Lightships of the National Data Buoy Center (National Oceanic and Atmospheric Administration) Channel, Greenwich and Sandettie located in the western and eastern English Channel and the southern North Sea, respectively

TELEMAC 2D predictions of the depth-averaged currents are evaluated. The current at points C1 and C2 predominantly flows south-east and ebbs north-west along the access channel to Port 2000 (Figure 3). The numerical results reproduce the flood/ebb asymmetry at the two measurements points characterized by (i) a magnitude of the flood three times greater than during ebb and (ii) a duration of the flood limited to four hours whereas extended to seven hours for ebb. This current asymmetry is characteristic of the tidal hydrodynamics of the Seine estuary (e.g, Avoine, 1981; Le Hir, Bassoulet and Jestin, 2001). The magnitude of the flood peak is approached with a difference lower than $15 \%$. A slight phase lag with an average value less than $15 \mathrm{~min}$ is however noticed in the comparison of the measured and predicted depth-averaged current directions. This difference appears to a lesser extend in the time series of the current speed. This tendency may be attributed to the flow inertia differences between the surface and bottom layers (e.g., Xie and Zhang, 2010). Whereas the current in the bottom layer is compelled to deflect to the channel direction in relation to restrictions by the bed friction and channel boundaries, the current in the surface layer could rotate freely. The flow direction varies therefore between layers while the speed distribution tends to be quite uniform. The $2 \mathrm{DH}$ circulation modeling constitutes however a satisfactory numerical approach of the tidal hydrodynamic conditions to be integrated in the wave propagation module.

TOMAWAC predicted time series of the wave height are compared with measurements at points $\mathrm{H} 1$ and H2 (Figure 4). When the effects of the tide are integrated (case CS, Table 1), the numerical results reproduce the semi-diurnal variation of the wave height. An overall good agreement is thus obtained between predictions and measurements. A slight overestimation of the wave height is however noticed at point H2 during the storms of 21 and 24 November 2008. This tendency is reduced at location H1 with a difference lower than $12 \%$ in 21 November 2008. Considering the difficulties to compute the tide-induced modulation of the wave height (e.g., Sørensen, Kofoed-Hansen and Jones; 2006), the present wave modeling seems acceptable to proceed further analysis.

\section{Local Effects of the Tide on the Wave Height}

The comparison of the predictions at points $\mathrm{H} 1$ and $\mathrm{H} 2$ between cases CS and NN (Table 1) exhibits the importance of the tide in the semi-diurnal wave height modulation near the harbor of Le Havre (Figure 4). The wave height (i) increases by about $30 \%$ at high tide and (ii) diminishes by about $10 \%$ at low tide in the access channel to Port 2000 (Figures 4-a, b and 5-a). These variations are consistent with the numerical estimates of Wang et al. (2006) who found a tide-induced increase of the wave height by 10-20 \% in the Pearl River estuary (China). 

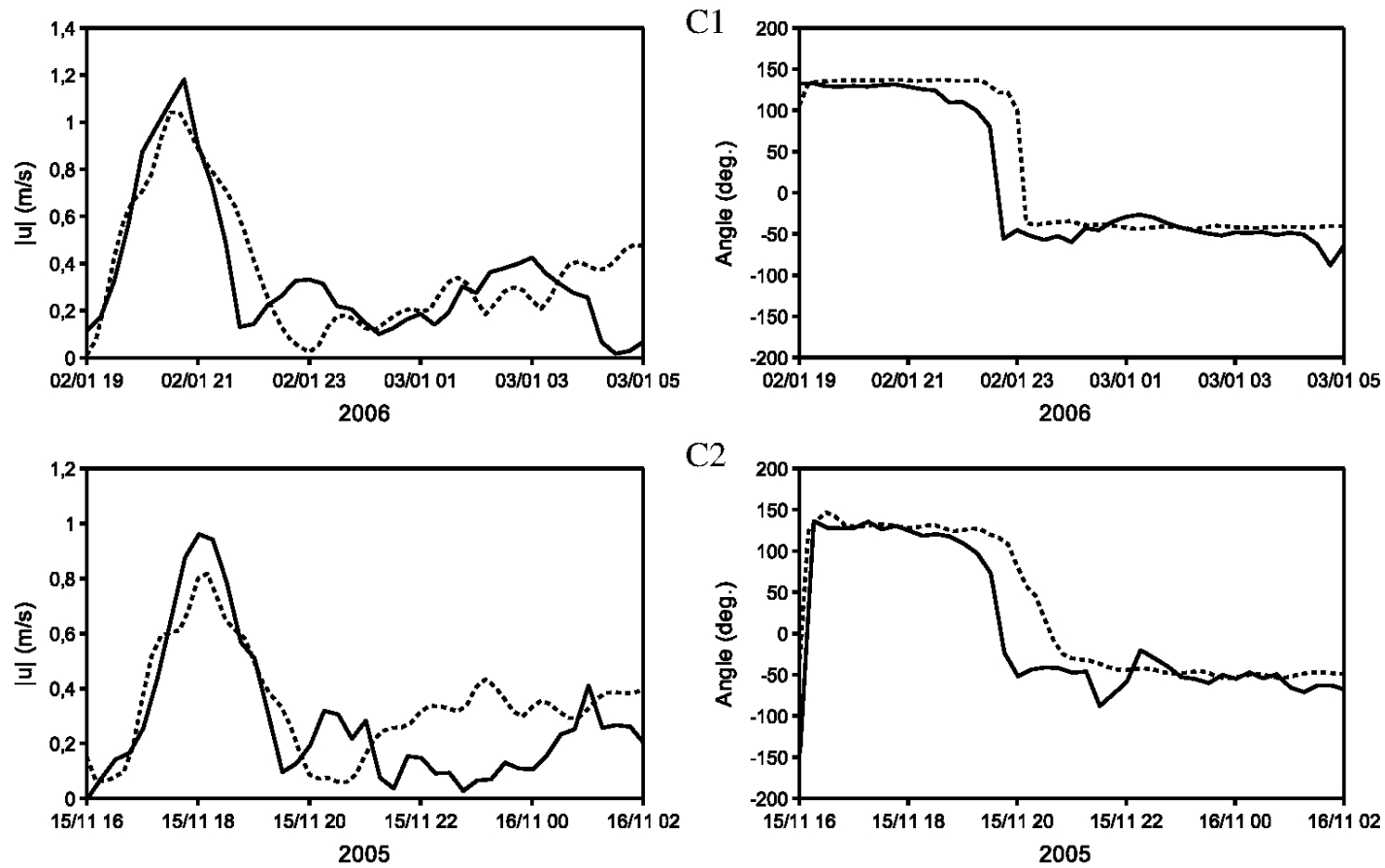

Figure 3: Measured (continuous line) and computed (dotted line) time series of the amplitudes and directions (clockwise from the north) of the depth-averaged currents at location C1 in January 2006 and location C2 in November 2005.

These modulations are however obtained at both locations (H1 and H2) between 9 and 25 November 2008 when the significant wave height exceeds the value of $0.60 \mathrm{~m}$ (Figure 4). The tide appears to have a negligible effect on the significant wave height in the beginning (1-9 November 2008) and the end (25-30 November 2008) of the measurement period when its value remains below $0.60 \mathrm{~m}$. Furthermore, the spring-neap tide cycle slightly modulates the effect of the tide on the significant wave height between 9 and 25 November 2008.

The effect of the tide on the wave height modulation are further investigated. The comparison of the local predictions between cases NS and CN (Table 1) exhibits the negligible effect of the time-varying water depths on the wave height modulation at points $\mathrm{H} 1$ and $\mathrm{H} 2$ thus leaving out the effects of water depths refraction and bottom friction dissipation. The currents appear to have a major influence on the wave height in the access channel to Port 2000. The role played by the tidal current is analyzed focusing on the storm of 9-13 November 2008 at point H2 (Figure 5). It seems difficult to assign these variations to waves steepening by the current as the maximum changes appear at slack tide when the current amplitude is minimum (Figure 5-a). The semi-diurnal wave height modulation in the access channel to Port 2000 may however be attributed to current-induced refraction. The wave height variation is thus closely correlated with the evolution of the direction of the incident waves (Figure 5-b). The main local changes appear at slack tide (T2) when the current component along the west-eastern wave direction presents the maximum spatial gradients in amplitude (Figure 6). This phenomenon characterizes the current-induced refraction (e.g., Holthuijsen, 2007). The wave turns towards the region with lower current amplitude thus exposing the measurements point to the incident waves when the tidal flow reverses from flood to ebb. The reverse from ebb to flood induces however weaker wave height decreases in relation to lower current amplitude spatial gradient at slack tide and the tidal asymmetry of the hydrodynamics. Such increase of the wave height is also obtained along the southern breakwater of Port 2000 at slack tide in spite of high current speed at the flood (T1) and ebb (T3) peaks.

The major effect of current-induced refraction on the wave height in the access channel to Port 
2000 explains the slight sensitivity of the predictions to the intensity of the tidal regime. The modulations of the significant wave height are thus more sensitive to the spatial gradient in amplitude of the current than to the current amplitude. This mechanism clarifies the difference in the modulation of the significant wave height between the storms of 21 and 23 November 2008 (Figure 4). A stronger increase of the significant wave height is thus obtained for the storm of 21 November 2008 as the peak of the storm is closer to the high tide. Finally, these processes may also explain the quality of the predictions at points $\mathrm{H} 1$ and $\mathrm{H} 2$ (previous section). Indeed, when waves steepening dominates, the model tends to underestimate the tidal variation of the wave height because of the difficult description of the physics of wave conditions close to blocking (Sørensen, Kofoed-Hansen and Jones, 2006).
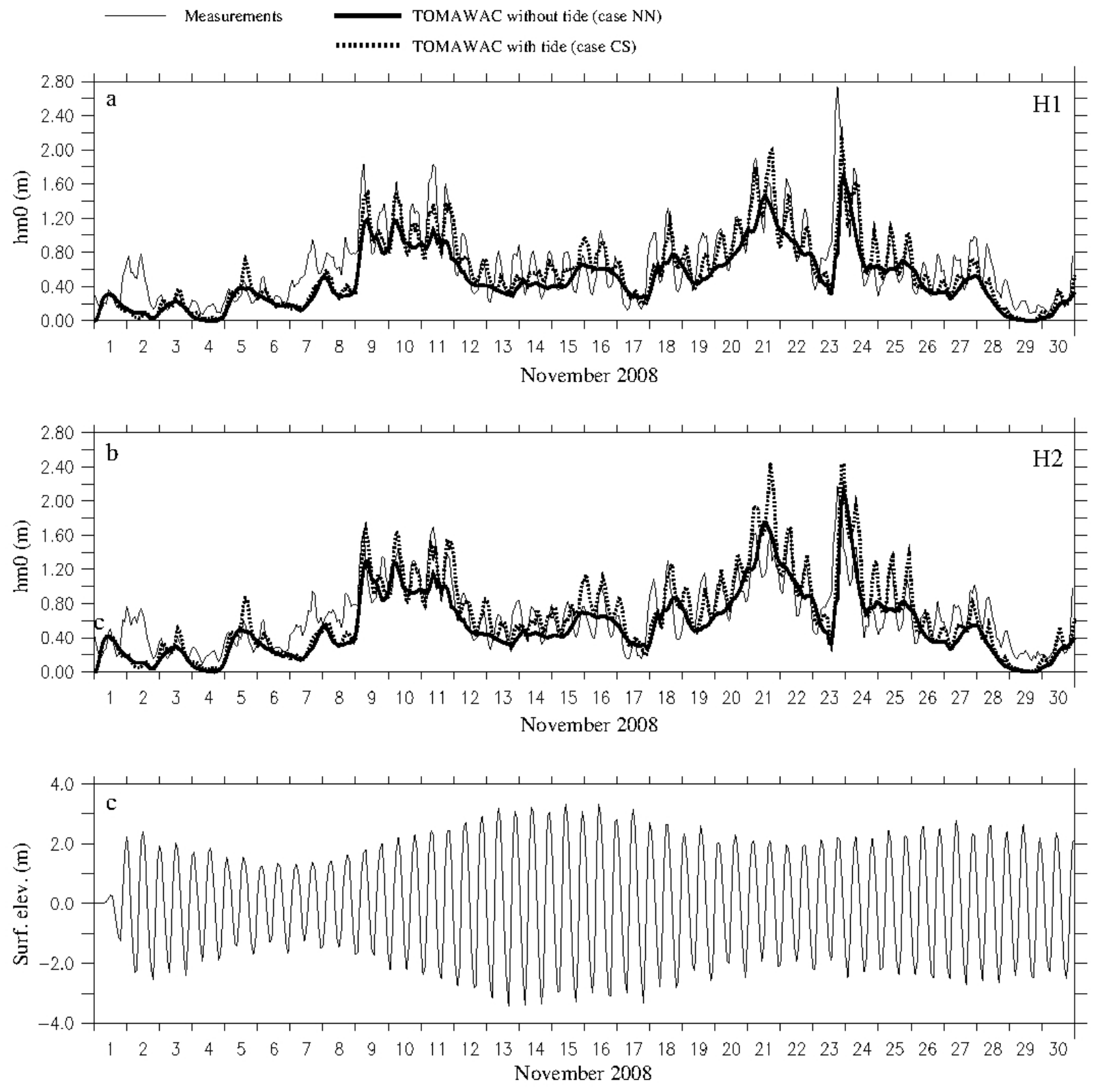

Figure 4: Measured and computed for cases CS and NN time series of the significant wave height at locations (a) H1 and (b) $\mathrm{H} 2$ and computed times series of (c) the free surface elevation at location H2 in November 2008. 

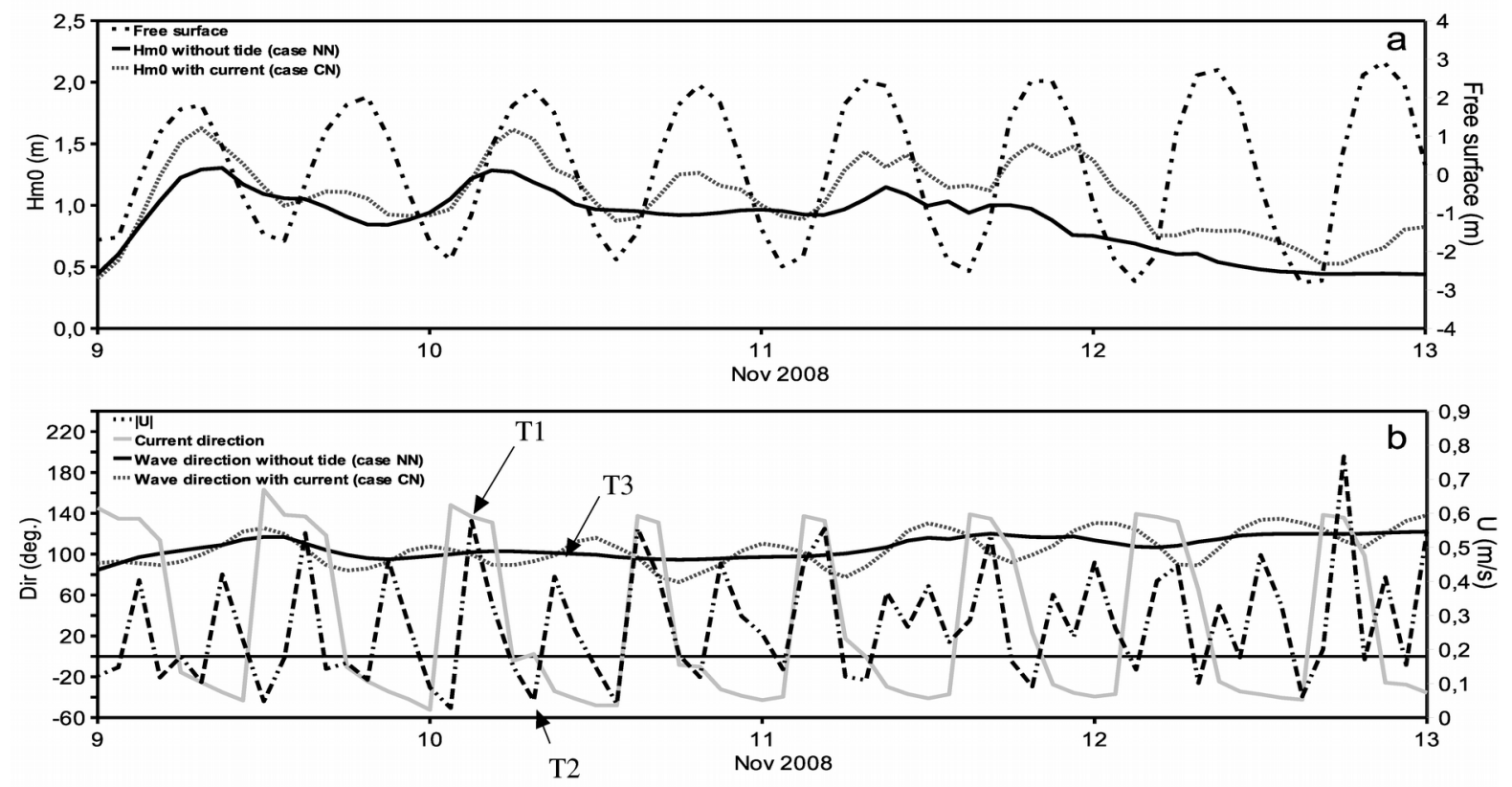

Figure 5: Predicted time series of (a) the significant wave height for cases $\mathrm{CN}$ and $\mathrm{NN}$ and the free surface elevation and (b) the wave direction (clockwise from the north) for cases CN and NN and the current amplitude and direction (clockwise from the north) at location H2 in 9-13 November 2008.

T1 - Flood peak
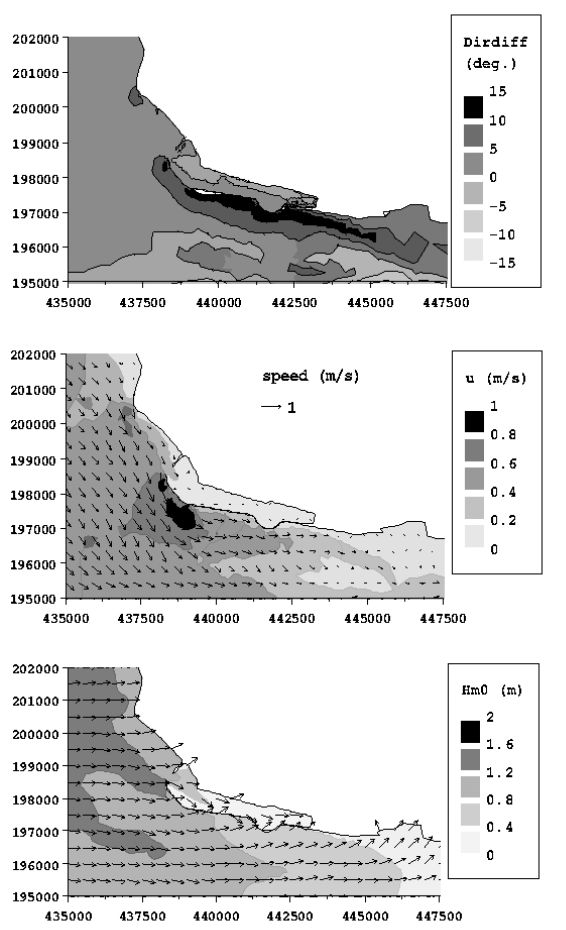

T2 - Slack tide
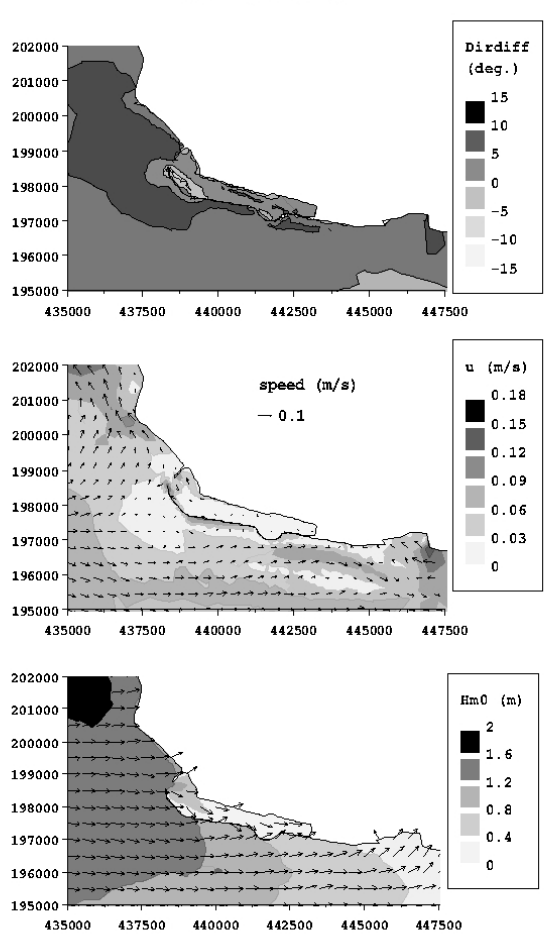

T3 - Ebb peak
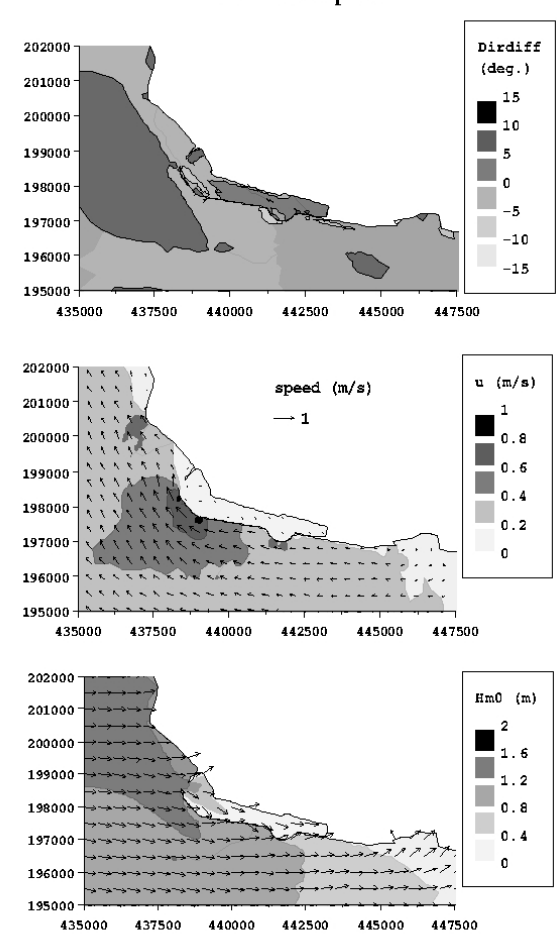

Figure 6: (Top) Differences of the wave directions between cases CN and NN, (Middle) the amplitudes and directions of the depth-averaged currents and (Bottom) the significant wave heights and directions for case CN at times T1, T2 and T3 in 10 November 2008 (Figure 5). 


\section{Regional Mappings of the Effects of the Tide on the Waves Height}

The numerical predictions are further exploited to produce a mapping of the areas of the outer Seine estuary where the wave heights are modified by the tide. This mapping is performed on the basis of the numerical predictions established in November 2008. A criterion is established to characterize the differences between the time series of the wave height from cases CS and NN. Liu and Xie (2009) considered the difference between the maximum wave heights over the period of simulation. This criterion requires however that the increase of the wave height by the tide appear at the peak of the storm to compare two consistent maximum values. Furthermore, it does not represent the overall wave height modulation by the tide over the period of simulation. The criterion retained here is the average of the absolute differences between the wave heights predicted from cases CS and NN.

The spatial distribution of this criterion identifies the areas where the wave height is influenced by the tide (Figure 7-a). This criterion takes the value of $0.11 \mathrm{~m}$ at point $\mathrm{H} 1$ and $0,14 \mathrm{~m}$ at point $\mathrm{H} 2$. At the scale of the Seine estuary, the average value is $0.12 \mathrm{~m}$ with maximum over $0.20 \mathrm{~m}$ in shallow waters and the access channels to the Seine river (Figure 7-a). The minimum values are obtained in the areas of low agitation, within the enclosure of Port 2000 and the mouth of the Seine river. Two complementary mappings are produced to characterize on the basis of the same criterion the areas influenced by the time-varying water depths (Figure 7-b) and currents (Figure 7-c), respectively. As identified locally in the access channel to Port 2000, the currents have a major influence on the wave height modulation in the Seine estuary with an average criterion of $0.11 \mathrm{~m}$. The time-varying water depths modulate however the wave heights in the shallow waters (i) off the cape of La Hève, (ii) the shoals of the Seine estuary entrance and (iii) along the southern coastline. The influence of the currents is particularly noticeable (i) at the western extremities of the access channel to the Seine river, (ii) off Villerville, (iii) close to the breakwaters of the harbor of Le Havre and (iv) off the cape of La Hève.

On the basis of these three mappings, eight typical locations in the outer Seine estuary are selected, in areas of maximum average absolute differences (points \#1 to \#5), offshore (points \#6 and \#7) and at the mouth of the Seine river (point \#8) (Figure 7-a). The time series of the significant wave height extracted at these different locations exhibit specific tidal modulation in relation to the dominant effect of the time-varying water depths and currents (Figure 8). Offshore (points \#6 and \#7), the tide induces slight modifications of the significant wave height whereas the waves conditions are the most significant. The very little exposed region of the Seine estuary (point \#8, $\mathrm{h}_{\mathrm{m} 0}<0.8 \mathrm{~m}$ ) shows weak tidal modulation of the significant wave height. In the shallow waters off the cape of La Hève (point \#1) and the entrance of the Seine estuary (point \#3), the wave height reduces periodically to zero following the evolution of the total water depth. Indeed, the dissipations of the wave energy by bottom friction and depth-induced breaking lead to a significant decrease of the wave height as the total water depths decreases. This modulation is however reduced along the southern coastline (point \#5) in relation to weak tidal range. The current leads globally to an increase of the significant wave height along the southern breakwater of the harbor of Le Havre (point \#2) and off Villerville (point \#4). This effect is particularly noticeable at point \#2 where the significant wave height increases from $1.7 \mathrm{~m}$ to $2.5 \mathrm{~m}$ at the peak of the storm of 23 November 2008. This increase is seemingly related to current-induced refraction as significant changes of the incident wave direction are identified in this area in relation to the current (Figure 9). Indeed, the local declination of the external breakwaters towards a north-western/south-eastern direction may increase the variation of the current amplitude along the incident wave direction and the resulting current-induced refraction. Complementary measurements of wave height and current are however required to identify these modulations more precisely. Nevertheless, the mapping of the changes of the incident waves directions between cases CN and NN (Figure 9) presents a global correlation with the areas of current-induced changes of the wave height in the outer Seine estuary (Figure 7-c). Current-induced refraction may thus played a role in areas characterized by significant changes of 
the wave height, (i) off the cape of La Hève and Villerville and (ii) along the external breakwaters of the harbor of Le Havre.
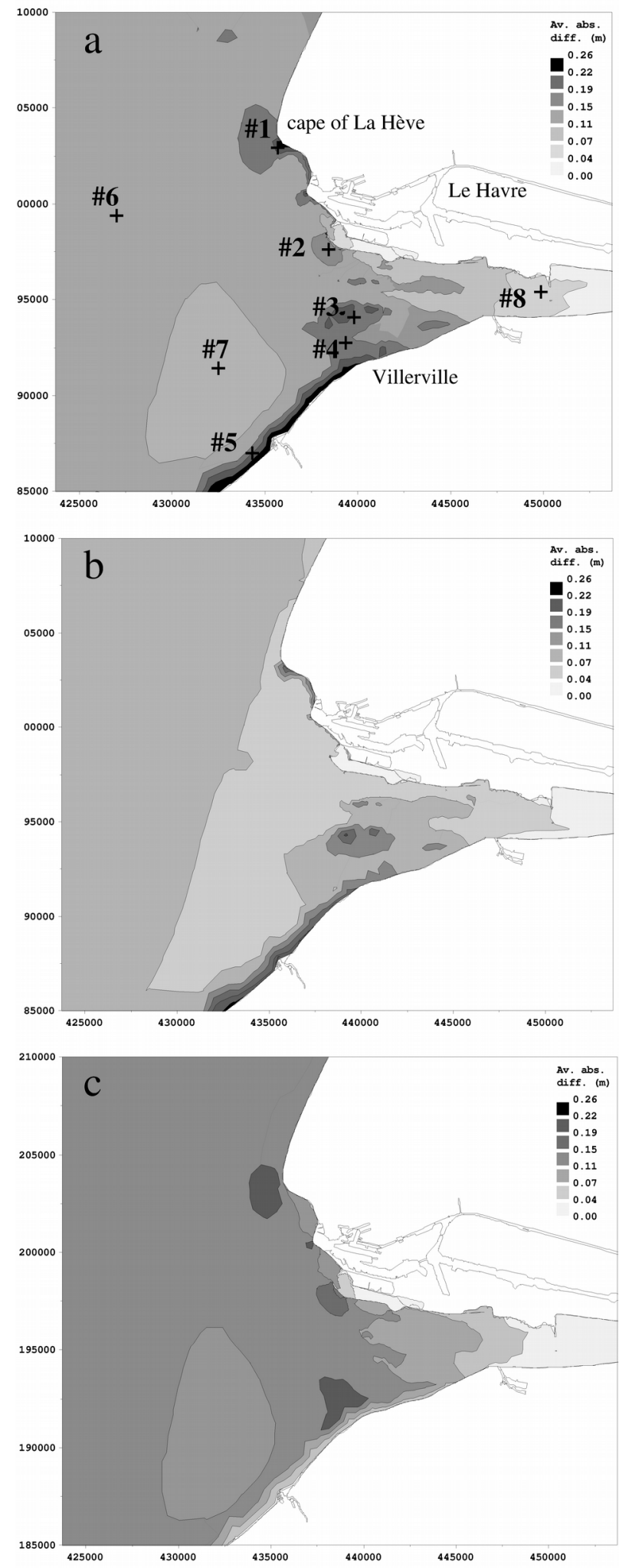

Figure 7: Average absolute differences of the significant wave heights between cases (a) CS and NN, (b) NS and NN and (c) CN and NN in November 2008. (a) Locations of the points \#1 to \#8 where the time series of the significant wave height are extracted. 

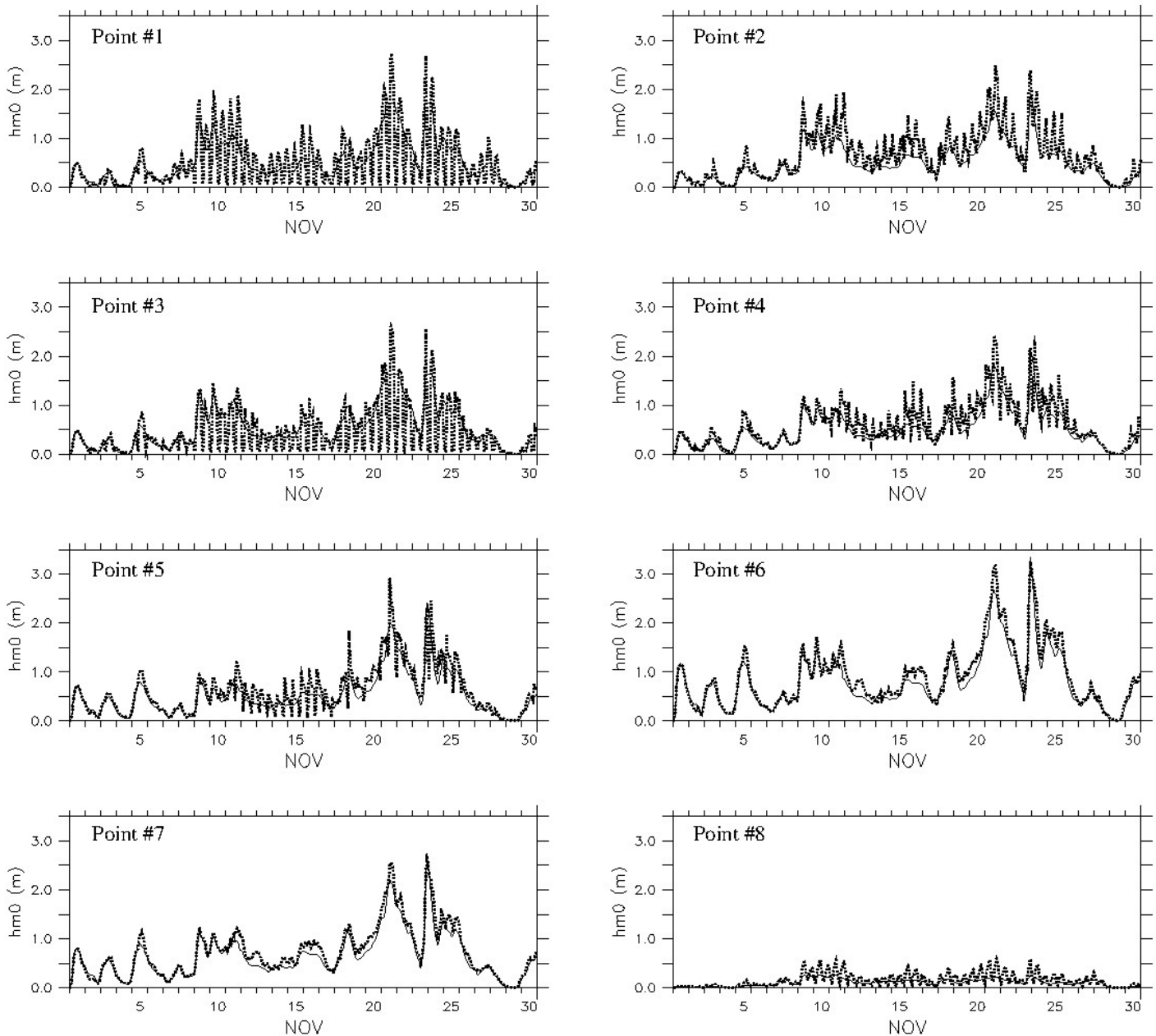

Figure 8: Time series of the predicted significant wave heights in cases CS and NN at points \#1 to \#8 in November 2008.

\section{CONCLUSIONS}

Nesting regional and local modeling system based on the coupling of wave propagation and circulation modules have been used to investigate the effects of the tidal time-varying water depths and currents on the wave height in the outer Seine estuary. Numerical predictions have been compared with measurements in the access channel to Port 2000 (harbor of Le Havre). The main outcomes of the present study are the following.

(1) The predicted time series of currents and wave heights show a fairly good agreement with measurements near the harbor of Le Havre. This comparison highlights the semi-diurnal modulation of the wave height by the tide.

(2) Current-induced refraction appears to be one of the main mechanism responsible for the tidal waves height variation in the access channel to Port 2000. The changes in the incident wave directions modulate the exposure of the measurements points thus increasing by about 30 $\%$ and decreasing by about $10 \%$ the wave height. Major changes appear at slack tide in relation to the spatial variation of the current amplitude along the incident wave direction.

(3) Three mappings of the wave heights modified by (i) the tide, the time-varying (ii) water depths and (iii) currents are established at the scale of the outer Seine estuary. At this regional scale, the tidal currents have a major influence on the wave heights variations. The main 
modulation appears (i) at the western entrance of the Seine river, (ii) off Villerville, (iii) close to the external breakwaters of the harbor of Le Havre and (iv) off the cape of La Hève.

The integration of the tide-induced time-varying water depths and currents in the wave modeling appears to be fundamental for an accurate estimate of the wave height variation and its extreme values during storm events in the outer Seine estuary. The present study has focused on the spatial extension at the scale of the outer Seine estuary of local results near the harbor of Le Havre. A prospective will consist in extending the simulation period to produce accurate wave climatologies of great benefit in areas like the harbor of Le Havre or the Seine river entrance. These developments will help to grow the experience of coupled circulation and wave modeling in estuaries. Finally, another aspects of this work will consist in simulating the effects of the tide on the wave agitation at the scale of the enclosure of Port 2000.

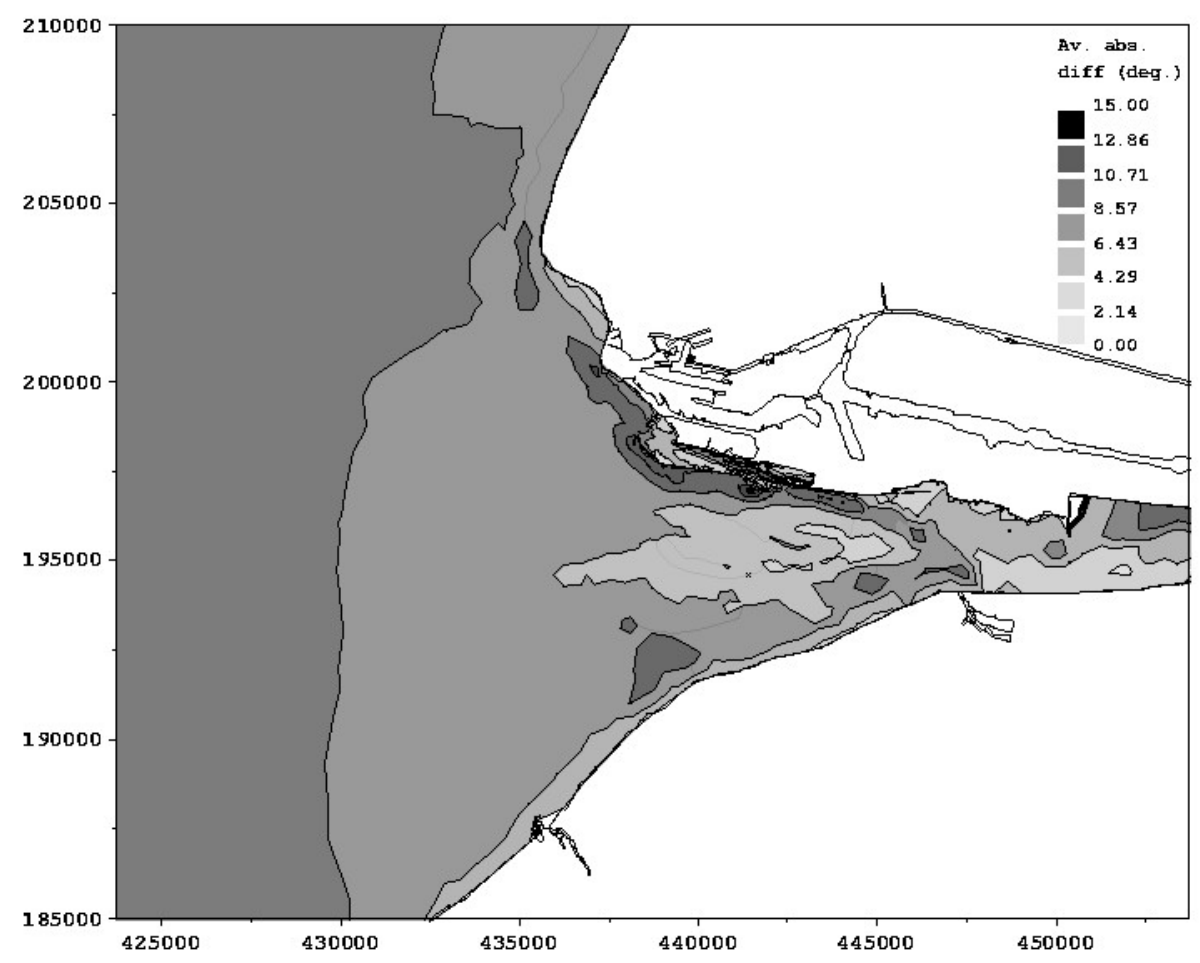

Figure 9: Average absolute difference of the wave direction between cases $\mathrm{CN}$ and $\mathrm{NN}$ in November 2008.

\section{ACKNOWLEDGMENTS}

The authors are particularly grateful to Ronan Schubel (Grand Port Maritime du Havre, France) for providing us with currents measurements in the access channel to Port 2000, to Dr. José Ozer (Management Unit of the North Sea Mathematical Models, Belgium) for supplying us with tidal harmonic constituents issued from a long term run of COHERENS at the scale of the North-West European continental shelf and to Dr. Fabrice Ardhuin (Institut Français de Recherche pour l'Exploitation de la MER, France) for giving us access to wave data issued from regional runs of WaveWatch III. Simulations were performed on computer facilities CAPARMOR (Calcul PARallèle Mutualisé pour l'Océanographie et la Recherche). The present paper is a contribution to the CETMEF-IUEM joint research program MEMPHYS (Mesure Et Modélisation des Processus HYdrodynamiques et hydro-Sédimentaires dans les écosystèmes côtiers) (http://memphyslgce.fr.ht/). 


\section{LITERATURE CITED}

Avoine, J., 1981. L'estuaire de la Seine : sédiments et dynamique sédimentaire. Thèse de doctorat de l'Université de Caen. 236 pp.

Benoit, M.; Marcos, F. and Becq, F., 1996. Development of a third generation shallow-water wave model with unstructured spatial meshing. Proceedings of the $25^{\text {th }}$ International Conference on Coastal Engineering, 465-478.

Booij, N.R.C.; Ris, R.C. and Holthuijsen, L.H., 1999. A third generation wave model for coastal regions, Part I, model description and validation. Journal of Geophysical Research, 104, 76497666.

Claasen, N.J., 2002. Modeling wave-current interaction in the vicinity of Humboldt Bay, California. Masters Thesis, Humboldt State University, 192 pp. URL http://cirp.usace.army.mil/pubs/html/02Thesis-Claasen.html

Davidson, M.A.; O'Hare, T.J. and George, K.J., 2008. Tidal modulation of incident wave heights: Fact or Fiction? Journal of Coastal Research, Issue 2, 151-159, DOI: 10.2112/06-0754.

Grant, W.D. and Madsen, O.S., 1979. Combined wave and current interaction with a rough bottom. Journal of Geophysical Research, vol. 84, n C4, 1797-1808.

Guillou, N., 2007. Rôles de l'hétérogénéité des sédiments de fond et des interactions houle-courant sur l'hydrodynamique et la dynamique sédimentaire en zone subtidale - applications en Manche Orientale et à la pointe de la Bretagne. PhD Thesis, Université de Bretagne Occidentale, 469 pp. URL http://tel.archives-ouvertes.fr/tel-00376679/en

Guillou, N. and Chapalain, G., 2010a. Storm waves-induced resuspensions of seabed sediments in the Dover Strait. Comparison of modelling results with measurements. European Journal of Environment and Civil Engineering, 14, 163-179.

Guillou, N. and Chapalain, G., 2010b. Numerical simulation of tide-induced transport of heterogeneous sediments in the English Channel. Continental Shelf Research, 30, 806-819.

Guillou, N.; Chapalain, G. and L. Thais, 2009. Three-dimensional modeling of tide-induced suspended transport of seabed multicomponent sediments in the eastern English Channel. Journal of Geophysical Research, vol. 114, C07025, doi:10.1029/2008JC004791.

Hasselmann, K. ; Barnett, T.P. ; Bouws, E. ; Carlson, H. ; Cartwright, D.E. ; Enke, K. ; Ewing, J.A. ; Gienapp, H. ; Hasselmann, D.E. ; Kruseman, P. ; Meerburg, A. ; Muller, P. ; Olbers, D.J. ; Richter, K., Sell, W. ; Walden, H., 1973. Measurements of wind-wave growth and swell decay during the Joint North Sea Wave Project (JONSWAP). Dtsch. Hydrogr. Z. Suppl. 12 (A8), 1-95.

Hervouet, J.M., 2003. Hydrodynamique des écoulements à surface libre. Modélisation numérique avec la méthode des éléments finis. Presses de l'Ecole Nationale des Ponts et Chaussées, Paris, 311 pp.

Holthuijsen, L.H., 2007. Waves in oceanic and coastal waters. Cambridge University Press, 387 pp. Huang, N.E.; Chen, D.T.; Tung, C.C. and Smith, J.R., 1972. Interactions between steady nonuniform currents and gravity waves with applications for currents measurements. Journal of Physical Oceanography, 2, 420-431.

Jonsson, I.G., 1990. Wave-current interactions. In: Le Mehaute, B.; Hanes, D.M. (Eds.), The Sea, vol. 9, Chapter 3.

Kanamitsu, M.; Ebisuzaki, W.; Woollen, J.; Yang, S.; Hnilo, J.; Fiorino, M. and Potter, G.L., 2002. NCEP-DOE AMIP II reanalysis (R-2). Bulletin of the American Meteorological Society, 83, 16311643.

Kang, K. and Di Iorio, D., 2006. Depth- and current-induced effects on wave propagation into the 
Altamaha River Estuary, Georgia. Estuarine, Coastal and Shelf Science, 66 (3-4), 395-408.

Le Hir, P.; Bassoulet, P. and Jestin, H., 2001. Application of the continuous modeling concept to simulate high-concentration suspended sediment in a microtidal estuary. Coastal Estuarine Sediment Processes, 229-247.

Lesourd, S., 2000. Processus d'envasement d'un estuaire macrotidal : zoom temporel du siècle à l'heure; application à l'estuaire de la Seine. Thèse de doctorat de l'Université de Caen, 280 pp.

Liu, H. and Xie L., 2009. A numerical study on the effects of wave-current-surge interactions on the height and propagation of sea surface waves in Charleston Harbor during Hurricane Hugo 1989. Continental Shelf Research, 29, 1454-1463.

Longuet-Higgins, M.S. and Stewart, R.W., 1960. Changes in the form of short gravity waves on long waves and tidal currents. Journal of Fluid Mechanics, 8, 565-583.

Luyten , P.J.; Jones, J.E.; Proctor, R.; Tabor, A.; Tett, P. and Wild-Aden, K., 1999. COHERENS: A COupled Hydrodynamical-Ecological model for RegioNals and Shelf seas - Part III - Model Description (Available on CD-ROM via http://www.mumm.ac.be/coherens). Management Unit of the North Sea Mathematical Models, Report MAS3-CT97-0088, Belgique, 911 pp.

Milbradt, P. and Plüß A., 2003. Numerical modelling of wave current interaction in an estuary. COPEDEC VI, Colombo, Sri Lanka.

Rusu, L. and Guedes Soares, C., 2007. Modelling of the wave-current interactions in Tagus estuary. In: Guedes Soares, C., Kolev, P. (Eds.), Maritime Industry, Ocean Engineering and Coastal Ressources, vol. II. Francis \& Taylor, London, 801-810.

Rusu, L.; Bernardino, M. and C. Guedes Soares C., 2011. Modelling the influence of currents on wave propagation at the entrance of the Tagus estuary. Ocean Engineering, 38, 1174-1183.

SHOM, 1996. Courants de marée en Baie de Seine de Cherbourg à Fécamp, Service Hydrographique et Océanographique de la Marine, 15 pp.

Signell, R.P.; Beardsley, R.C.; Graber, H.C. and Capotondi, A., 1990. Effect of wave-current interaction on wind-driven circulation in narrow, shallow embayment. Journal of Geophysical Research, 95, 9671-9678.

Sørensen, O.; Kofoed-Hansen, H. and Jones, O.P., 2006. Numerical modeling of wave-current interaction in tidal areas using an unstructured finite volume technique. Coastal Engineering, 653665, doi: 10.1142/9789812709554 0056.

Tolman, H.L., 2008. A mosaic approach to wind wave modeling. Ocean Modelling, 25, 35-47.

Waeles, B., 2005. Modélisation morphodynamique de l'embouchure de la Seine. Thèse de doctorat de l'Université de Caen - Basse-Normandie, 230 pp.

Wang, C.-H.; Wai, W.-H.; Onyx; Li, Y.-S. and Chen, Y., 2006. Modelling of the wave-current interaction in the Pearl River Estuary, Journal of Hydrodynamics, Ser. B., vol. 18, Issue 3, Supplement 1, 159-165.

Xie, M.-x. And W. Zhang, 2006. Numerical study on the three-dimensional characteristics of the tidal current around the harbor entrance, Journal of Hydrodynamics, 22, 6, 847-855.

\section{RESUME}

Au cours des dernières décennies, de nombreux modèles ont été mis en œuvre pour améliorer l'estimation des effets de marée sur les paramètres de la houle. La présente étude analyse les effets de la marée en termes de niveaux d'eau et de courants sur les hauteurs de houle dans l'estuaire externe de la Seine (France, Manche). Deux chaînes de modélisation couplant des modules de circulation et de propagation de houle sont appliquées aux échelles régionales de la Manche et de la 
Mer du Nord et locales de la baie de Seine et des infrastructures du port du Havre. Les résultats numériques sont comparés aux observations de deux courantomètres et deux houlographe dans le chenal d'accès à Port 2000. Ces prédictions montrent une augmentation de $30 \%$ de la hauteur de houle induites par la réfraction par les courants aux phases d'étale de la marée. Enfin, trois cartographies des hauteurs de houle modifiées par (i) la marée, (ii) les niveaux d'eau seuls et (iii) les courants seuls sont établies à l'échelle de l'estuaire externe de la Seine. Les courants ont une influence majeure sur la hauteur de houle modulant l'exposition aux houles incidentes à travers le phénomène de réfraction. Cette influence est particulièrement visible le long de la digue Sud du port du Havre et à proximité des accidents topographiques côtiers de l'estuaire externe de la Seine. 